\title{
Yürüyüş Terminolojisi
}

\author{
Prof.Dr. Serap Alsancak \\ Ankara Üniversitesi Sağllk Hizmetleri Meslek Yüksekokulu \\ Fatih Caddesi, 197/A, Keçiören, Ankara \\ e-mail:alsancak@ankara.edu.tr

\section{Özet}

$\mathrm{Bu}$ yazıda yürüyüş ile yürüyüş terminolojisi, yürüyüş periyodu, yürüyüş parametreleri tanımlanarak kinezyoloji, protez, ortez, rehabilitasyon dersleri alan üniversite öğrencilerimize bilimsel temel oluşturmak ve protez-ortez alanında çalş̧an ekip elemanlarına yapacakları hizmette katkı sağlamak amaçlanmıştır.

Anahtar kelimeler: Yürüyüş, terminoloji.

\section{Summary}

The aim of this article in defining of gait with gait terminology, gait cycle, gait parameters is to provide and create scientific basis to the university students' courses such as kinesiology, prosthetics, orthotics, rehabilitation to contribute to the working team members' services in the prosthetic and orthotic field.

Key words: Gait, terminology.

Normal yürüyüş paremetrelerinin iyi bilinmesi Protez ve Ortez alanında çalışan ekibin ürettikleri, uyguladıkları veya rehabilitasyonunu gerçekleştirdikleri alt ekstremite protez ve ortezlerini kullanan kişilerin, normale ne ölçüde yakın bir yürüyüş yapabildiklerini değerlendirmeleri ve çözüm getirici üretimsel, mekanik veya rehabilitatif uygulamaları gerçekleştirmesini sağlaması bakımından önem taşımaktadır.

Alt ekstremite ortezleri kullanılma amaçları ve yapımında yararlanılan malzemeler yönüyle farkl1lık gösterir. Örneğin bir ayak bilek ortezi (AFO) ayak bileği hareketini güçlü kaslar yönünde kısıtlayarak fonksiyonel yönden zayıf olan kaslara yardımcı olur ve güvenli bir hareketin gerçekleşmesini sağlar.

Alt ekstremite protez kullanıcıları çoğu kez kendileri için güvenli bir yürüyüş paterni geliştirirler. Ancak protez aksamlarındaki gelişmeler onların daha doğal ve rahat yürümelerine katkı sağlar. $\mathrm{Bu}$ amputelerde önemli hususlardan biri vasküler nedenli geriatrik transfemoral amputelerde her iki alt ekstremite kas gücünü geliştirecek ve protezle yürüyüşü kolaylaştırıcı mekanik önlemleri almaktır.

Bu yazı ile yürüyüş, yürüyüş periyodu, yürüyüş parametreleri detaylı gözden geçirilerek alan öğrencilerine ve çalışanlarına bilimsel katkı amaçlanmıştır.

\section{Yürüyüş}

Yürüyüş, gravite merkezinin sagital düzlemde öne doğru yer değiştirmesi ile birlikte gövdenin ve ekstremitelerin ritmik alternatif hareketleri olarak tanımlanmaktadır. Bu sırada alt ektremite segmental hareketine, üst ekstremite segmentleri ve gövde hareketleri iştirak eder. ${ }^{7}$ 
Yürüyüşün tarihçesine bakıldığında matematiksel analiz ve matematiksel modellemeye dayanan tanımlayıcı çalışmalar ve ölçüm metodları dikkat çekicidir. Yürüyüş analizine yönelik yarım asır öncesine dayanan Garrison, Bresler ve Frankel ve Steindler'in önemli çalışmaları ile günümüzde Sutherland'in klinik analiz temelli üç önemli çalışmasıdır. ${ }^{2,3,11,12}$

Yürüyüşün tanımlanmasında yıllardır farklı metotlarla belirlenen kinematik değerlendirmeler, kuvvet platformuları, elektromyografik verilerle elde edilen kas aktivite değerleri, mekanik analizler ve matematiksel modellemeler normal yürüyüş parametrelerini belirlemede önemli etken olmuş ve klinik çalışmalarda yerini almıştır.

\section{Yürüyüş̧ Periyodu (Gait Cycle)}

Yürüyüş periyodu, bir ayağın yerle teması (initial contact) ile aynı ayağın ikinci kez yerle teması arasında oluşan olaylardır. Perry ve ark. yürüyüş periyodunun zaman ve mesafe parametrelerini sınıflandırmışlardır ${ }^{6,7} \mathrm{Bu}$ sınıflandırmada geçen 7 evre veya subgrup vardır. Bunlar sırası ile initial contact, karşı ayakta toe off, heel rise, karş1 ayakta initial contact, toe off, feet adjacent, tibia vertical'dir. Bu olaylardan 4'ü stance fazda gerçekleşir. Diğer 3'ü ayağın havada olduğu swing fazdadir. ${ }^{7}$

Stance faz veya diğer bir terminoloji ile yürüyüşün destek veya temas fazı, initial contact'la başlar ve toe off'la sonlanır. Bu hareketler stance'in 4 evresi içinde olur. Bunlar looding response, mid-stance, terminal stance ve pre-swing evreleridir. Swing faz, toe off' la başlar ve aynı ayağın ikinci initial contact'1 ile sonlanır. Bu faz 3 evreyi içinde barındırır. Bunlar initial swing, mid-swing ve terminal swing'dir (Şekil 1). ${ }^{7}$

Initial contact (IC): Heel contact olarak da tanımlanır. İlk temastır. Ayağın yerle ilk temas ettiği anda gerçekleşen iki aktiviteyi heel strike (topuk vuruşu) ve foot flat (taban teması)'i içine alır.

Opposite toe off (OT): Foot flat esnasında diğer ayakta görülen parmakların kalkışını tanımlar.

Loading response: Yüklenmeye cevaptır. Initial contact ile başlar ve opposite toe off'a kadar devam eder. Bu bir ayağın yerle temasından diğer ayak parmaklarının kalkışına kadar olan süreçtir.

Mid-stance: Opposite toe off'la başlar ve aynı ekstremitedeki heel rise ile sonlanır. Diğer ayak parmaklarının kalkışı ile başlayan süreçte vücut ağırlığı öndeki ekstremite üzerine bütünüyle verilir ve takip eden süreçte topuk kalkışa hazırlanır ve yükselir.

Heel rise (HR): Heel off olarak da tanımlanan topuk kalkışı aynı zamanda push off (itme) fazının başlangıcını oluşturur ve terminal stance döneminde gerçekleşir.

Opposite initial contact (OI): Diğer ekstremitenin topuk temasıdır. Stance'in sonunda görülür.

Terminal stance: Son destek veya son duruş fazı olarak tanımlanır. Bir başka ifade ile stance'in sonudur. Heel rise ile başlar ve opposite initial contact ile sonlanır. Bir bakıma topuk kalkışı ve itmenin gerçekleştiği dönemdir. Bu dönemde bir ekstremite stance'ini ve diğer ekstremite swing faz'ını sonlandırır.

Toe off (TO): Parmakların yerden kalkışıdır. Pre-swing faz'ın önüne rastlar.

Pre-swing: Salınım veya sallanmaya geçiş öncesi olan ve terminal stance'i takiben görülen son aktiviteleri barındırır. Opposite initial contact ile başlar ve aynı ayağın toe off'u ile sonlanır. Diğer ayak topuk temasını gerçekleştirirken, aynı ayak parmaklarında kalkış görülür.

Feet adjacent (FA): Ayakların birbirini yakaladığı andır. Initial swing'in sonu ve mid-swing'in başlangıcını olşturan bir aktivitedir.

Initial swing: Pre-swing'i takibe görülür ve toe off'la başlayıp feet adjacent ile sonlanır. Bu fazda parmakların kalktığı ayak diğer ayağı yakalar. 
Vertikal Tibia (TV): Tibianın vertikal konumlandığı andır. Mid-swing fazı'nın sonunda gerçekleşen bu aktivite aynı zamanda terminal swing'in de başlangıcını oluşturur.

Mid-swing: Orta sallanma fazıdır. Havadaki ayağın yerdeki ayağı yakaladığı ve öne geçtiği süreci kapsar. Mid-swing başlangıcında ayaklar birbiriyle buluşmuşken, sonunda havadaki ayak öne geçmiş ve tibia vertikal konuma gelmiştir.

Terminal swing: Son sallanma fazıdır. Tibianın vertikalleştiği konumla başlar ve aynı ayağın initial contact'ı ile sonlanır. Böylece bir yürüyüş periyodu tamamlanmış olur. ${ }^{7}$

Tüm bu terminolojilerle birlikte alternatif terimler de bugüne kadar kullanılmıştır ve kullanılmaktadır. Özellikle Wall ve arkadaşları bazı yürüyüş patolojilerinde belirtilen bu terimlerin dışında terimleri kullanmayı tercih etmişlerdir. ${ }^{1,15}$

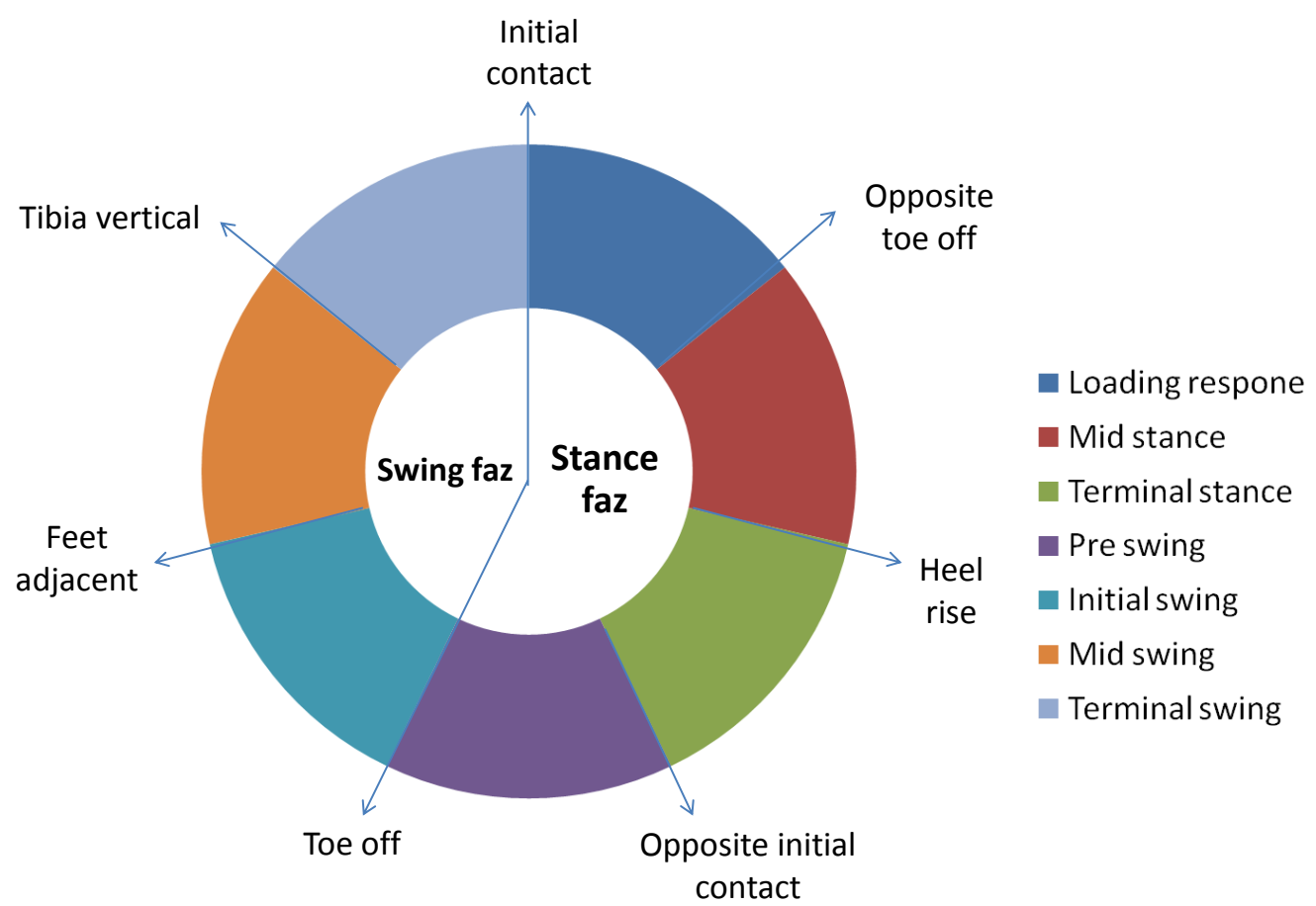

Şekil 1. Bir yürüyüş periyodu (sağ ayak için)

(Whittle's Gait Analysis'den alınmıştır)

Yürüyüş periyodunda ayağın yerle teması 3 destek fazı ile tanımlanır.

Double support : Çift destek fazı'dır. Double limb stance de denir. Örneğin sağ ayak için IC gerçekleşirken sol ayakda TO olur. Çift destek fazında bir ayak ilerdedir ve henüz yere değmiştir ve diğer ayak yerden ayrılmak üzeredir.

Right single support: Sağ tek destek fazıdır. Single limb stance de denir. Sol tarafın swing fazının IC ile sonlanması anıdır. Sol TO ile sol IC arası fazdır.

Left single support: Sol tek destek fazıdır. Single limb stance de denir. Sağ swing fazdadır ve sağın IC'1 ile sonlanır. Sağ TO ve sağ IC arası fazdır. Her yürüyüş periyodunda 2 çift destek ve 2 tek destek periyodu bulunur (Şekil 2). Koşmada ise çift destek periyodu yerini uçuş fazına veya flight faza bırakır ki bu çift desteğin olmadığı faz olup non-support faz şeklinde de tanımlanır. 


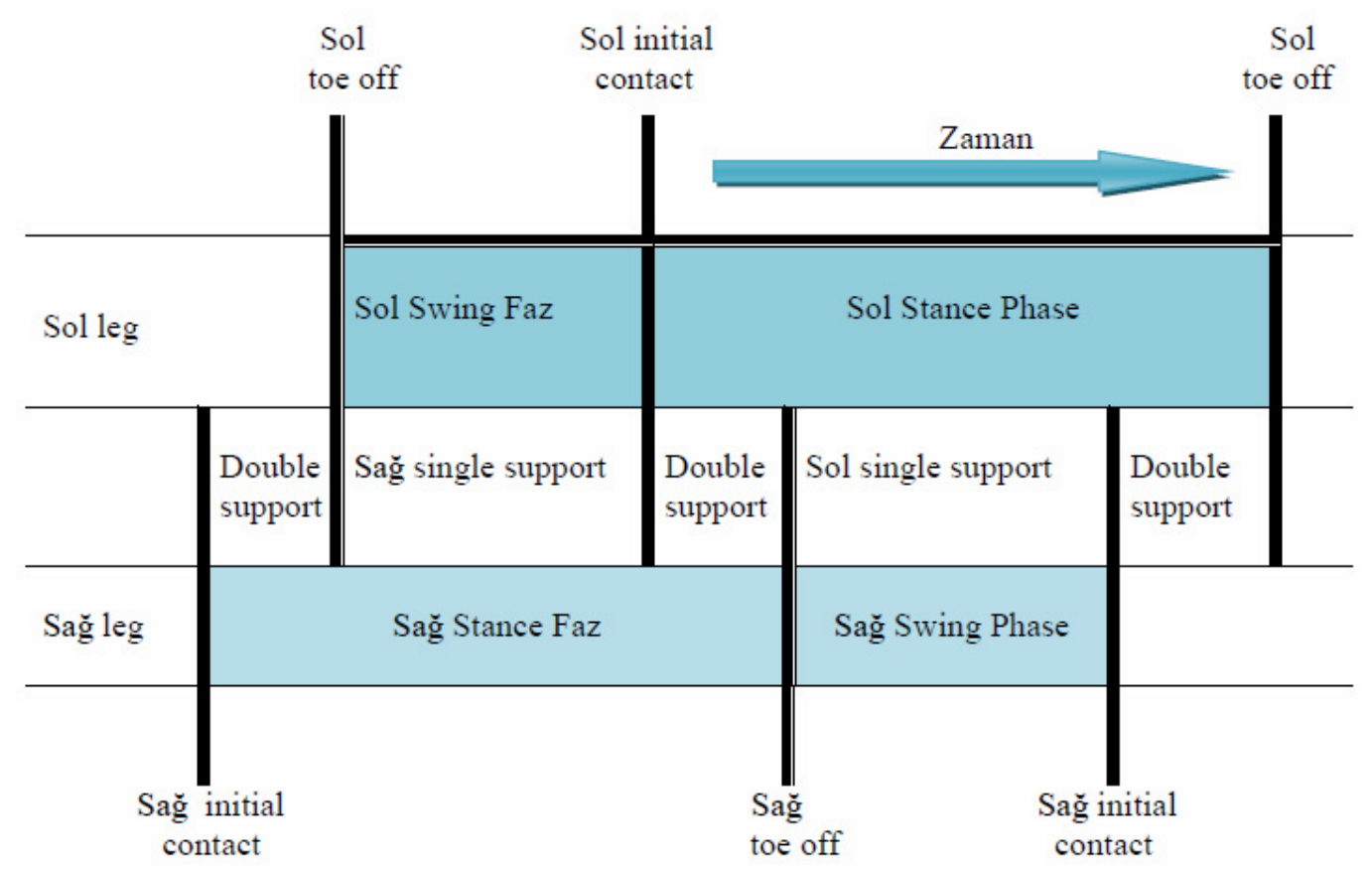

Şekil 2. Çift ve tek destek periyotları (Whittle's Gait Analysis'den alınmıştır)

\section{Yürüyüşün Zaman ve Mesafe Parametreleri} vardır.

Bir yürüyüş siklusunda bireye göre değişen yürüyüş hızı, kat edilen mesafe, kadans ve ritimi

Adım uzunluğu: Bir topuğun yere temas eden noktası ile diğer topuğun yere temas eden noktası arasındaki mesafedir. Bu sağ adım uzunluğu veya sol adım uzunluğu şeklinde olur.

Çift adım uzunluğu: Bir topuğun yere temas eden noktası ile aynı topuğun yere temas eden noktası arasındaki mesafedir. Sağ ve sol adım uzunluklarının toplamına eşittir. Stride length olarak tanımlanır.

Adım genişliği: İki topuk orta noktası arasındaki horizontal mesafedir. Bu mesafe birbirinden uzaksa pozitif, çaprazlıyorsa negatif olarak kaydedilir.

Kadans: Belirli bir zamandaki adım sayısıdır. Genellikle dakikadaki adım sayısı olarak hesaplanir.

Hız: Belirli bir zaman diliminde vücudun aldığı mesafedir.

Ayak açısı: Ayağın uzun ekseni (topuk orta noktası ile 2.-3. parmakların orta noktası arasında uzanan eksen) ile kalkaneusların orta noktasını birleştirmesi ile elde edilen ilerleme hattı arasındaki açıdır. ${ }^{2,4,5-10}$ 


\section{Yürüyüşün Genel Özellikleri}

Yürüyüşün genel özellikleri yürüyüş determinantları olarak ilk Saunders ve ark (1953) tarafindan tanımlanmıştır. Düzgün ve eforsuz yürüyüş normal yürüyüş olarak değerlendirilir. Sakral ikinci vertebranın önünde bulunan gravite merkezi yürüyüss sırasında sinüzoidal bir eğri üzerinde hareket eder. Frontal düzlemde pelvis her adımda $4-5 \mathrm{~cm}$ yukarı ve $4-5 \mathrm{~cm}$ aşağı olmak üzere 9-10 cm'lik hareket eder. Transvers düzlemde ise 4 derece sağa ve 4 derece sola pelvik rotasyon olur.

Normalde yürüyüş hızı $80 \mathrm{~m} / \mathrm{dk}$ 'dır. Hızlı yürüme ve koşmada daha fazla anaerobik metabolizma gerekir. Yavaş yürümede ise dengeyi sağlayabilmek için ekstra enerji harcaması söz konusudur.

Birçok hastalıkta gravite merkezinin vertikale ve laterale yer değiştirmesi artar ve bu durum yürümede aşırı enerji tüketimine neden olur. Yürüyüş bozukluklarında rehabilitasyonun önemli amaçlarından biri aşırı enerji tüketimini azaltmaktır.

Yürüyüş hızı $(\mathrm{m} / \mathrm{sn})=$ stride length $(\mathrm{m}) \mathrm{x}$ cadence $(\mathrm{ad} / \mathrm{m} / \mathrm{dk}) / 120$ şeklinde hesaplanabilir.

Yürüyüşün kinetik ve kinematik değerleri normal şartlarda yürüyüş periyodunda eklemlerde ve kaslardaki değişimi inceler. Kinetikte eklemlerin hareketine yol açan kasların aktiviteleri gravite ve yer reaksiyonuna göre analiz edilir. Kinematikte ise, eklem ve ekstremite segmentlerinin açısal değerleri tanımlanır. ${ }^{4-6,12-14}$

\section{Kaynaklar}

1. Ayyappa E. Normal human locomotoin. Part I: Basic concept and terminology. JPO, 1997, 9:1017

2. Bresler B and Frankel. The forces and moments in the leg during level walking. American Society of Mechanical Engineers Transactions, 1950, 72: 27-36.

3. Garrison FH. An Introduction to the History of Medicine, WB Saunders, Philadelphia, 1929.

4. Hughes J. Biomechanics and Prosthetics in Amputation. Ed. G Murdoch and B Wilson, Butterworth Heinemann, Oxford, 1996, ss. 13-19.

5. Jones K, Barker K. Human Movement Explained, Butterworth Heinemann, Oxford 1996, ss. $297-$ 314.

6. Kernigan DC, Schaufele M, Wen MN. Gait analysis In: Rehabilitation Medicine: Principles and practice Ed. JA Delisa and BM Gans 3rd ed. Lippincott Raven Publish, Philadelphia, 1998, ss. 167-186.

7. Levine D, Richard J and Whittle MW. Whittle's Gait Analysis, Churchill Livingstone, Edinburgh, 2012, ss. 32-39.

8. Perry J. Normal gait. In: Atlas of Limb prosthetics: Surgical, Prosthetic and Rehabilitation Principles. Ed. JH Bowka and JW Michael. $2^{\text {nd }}$ ed, CV Mosby, St Louis, 1992, ss. 359-371.

9. Perry J. Normal gait. In: Atlas of Amputations and Limb Deficiencies: Surgical, Prosthetic and Rehabilitation Principles. Ed. DG Smith, JW Michael, JH Bowker. $3^{\text {rd }}$ ed, Rosemont, IL, ss. 353365.

10. Smidt GL, Wyatt MP. Rudiments of gait, Gait in children. In: Gait in Rehabilitation. Ed. GL Smidt, Churchill Livinstone, New York, 1990, ss. 1-47, 157-184.

11. Steindler A. A history review of the studies and investigations made in relation to human gait. $\mathrm{J}$ Bone Joint Surg Am, 1953, 35: 540-542.

12. Sutherland DH. The evolution of clinical gait analysis. Part I: Kinesiological EMG. Gait Posture, 2001, 14, 61-70. 
13. Sutherland DH. The evolution of clinical gait analysis. Part II: Kinematics. Gait Posture, 2002, 16, 159-179.

14. Sutherland DH. The evolution of clinical gait analysis. Part III: Kinetics. Gait Posture, 2005, 21, 447-461.

15. Wall JC, Charteris J and Turnbull GI. Two steps equals one stride equals what? The applicability normal gate nomenclature to abnormal patterns. Clin Biomech,1987,2 119-125. 